\title{
The effectiveness of Keynes-Tobin transaction taxes when heterogeneous agents can trade in different markets: A behavioral finance approach
}

Frank H. Westerhoff, University of Osnabrueck, Department of Economics

\begin{abstract}
We develop a model in which boundedly rational agents apply technical and fundamental analysis to identify trading signals in two different speculative markets. Whether an agent trades and, if so, in which market with which strategy depends on profit considerations. As it turns out, an ongoing evolutionary competition between the trading strategies causes complex price dynamics which closely resembles the behavior of actual speculative prices. Moreover, we find that if the agents have to pay a transaction tax in one market, price variability decreases in this market but increases in the other market. However, the imposition of a uniform tax on all transactions stabilizes both markets. Our results suggest that if regulators of a market introduce a transaction tax, other markets are likely to follow.
\end{abstract}

\section{JEL classification}

D84, G14, G18

\section{Keywords}

speculative markets, transaction tax, heterogeneous agents, technical and fundamental analysis

\footnotetext{
* Contact: Frank H. Westerhoff, University of Osnabrueck, Department of Economics, Rolandstrasse 8, D-49069 Osnabrueck, Germany. Email: fwesterho@oec.uni-osnabrueck.de.
} 


\section{Introduction}

According to classical theory, asset prices properly reflect their fundamentals since arbitrageurs quickly counter mispricings. Keynes (1936) doubted this hypothesis and provided a quite contrasting view of financial markets. He argued, for instance, that many persons lack the capability to compute fundamentals correctly. Instead, they are subject to waves of optimistic and pessimistic sentiment. Prices may thus change violently as the result of a sudden shift of opinion. In addition, day-to-day changes in fundamentals may have an excessive impact on prices. Incentives to correct the vagaries of "ignorant" investors are limited. On the contrary, most "expert" investors are concerned with outwitting the crowd. What matters is not what an investment is really worth but what the crowd thinks how the crowd will evaluate it. Such behavior may not be unreasonable: Investment funds are often managed by committees who desire quick profits. Furthermore, investors who ignore shortterm fluctuations also need greater resources for safety.

Keynes concluded that pure laissez-faire capitalism does not fulfill its social purpose. The influence of speculation is so enormous that new investments are not directed into the most profitable channels in terms of future yields. The introduction of a transaction tax might prove the most serviceable reform available, mitigating the predominance of destabilizing short-term speculation over stabilizing long-term investment. Keynes' suggestion obtained new momentum when Tobin (1978) proposed the imposition of a uniform tax of around 1 percent on all currency transactions in order to placate foreign exchange dynamics. Nowadays, a levy of between 0.05 and 0.5 percent is discussed (for surveys see, e.g. Eichengreen et al. 1995, Haq et al. 1996, Frankel 1996, Spahn 2002). Even such small tax rates still have a strong impact on high-frequency trading. For example, if the tax rate is 0.05 percent, then a person who goes in and out of the market once a day accumulates an annual tax burden of about 43 percent. Long-term investors are, of course, less strongly penalized. 
Although the Keynes-Tobin transaction tax mechanism is vividly debated in the popular media, academic scrutiny has until now remained scant. One reason was the lack of theoretical models that take into account the action of heterogeneous speculators. Fortunately, this obstacle has dissolved with the advent of the chartist-fundamentalist approach. Contributions by, e.g. Day and Huang (1990), Kirman (1991), Lux (1995) or Brock and Hommes (1997) show that the behavior of heterogeneous boundedly rational agents who rely on technical and fundamental analysis may endogenously create complex price dynamics. These models, which are in harmony with Keynes' (1936) view of financial markets, have clearly improved our understanding of what is going on in the markets.

The goal of this paper is twofold: To develop a simple chartist-fundamentalist model in which agents can trade in two speculative markets and to investigate how transaction taxes alter the dynamics. Within our model, agents have five options. They may apply technical or fundamental analysis in market 1 or 2 , or they may abstain from trading. The agents tend to pick those rules which did well in the past. Simulations show that the model's dynamics resembles those of actual markets quite closely. We observe intricate price motion, bubbles and crashes, high volatility, excess kurtosis, and clustered volatility. The dynamics is driven by an enduring evolutionary competition between the trading strategies. For instance, when chartism becomes popular, volatility increases and severe bubbles may emerge. Transaction taxes affect the competition between trading strategies in a non-trivial way. Suppose a small tax is imposed in market 1 . Then market 1 is stabilized but market 2 is surprisingly destabilized. Although some agents retreat from trading, some destabilizing speculators also migrate from market 1 to market 2 . If the agents have to pay a uniform levy in both markets, chartism declines in favor of fundamentalism in both markets and thus both markets display lower price fluctuations and deviations from fundamentals. Hence, there is no reason for regulators of a market not to impose such a tax - at least the own market will benefit. 
The remainder of this paper is organized as follows. Section 2 briefly reviews the chartist-fundamentalist approach. In section 3, we present a model in which investors can switch between two markets. In section 4, the model is calibrated to speculative markets. Section 5 studies the impact of transaction taxes and the last section concludes the paper.

\section{Survey of the literature}

Experimental evidence has long suggested that people generally lack the computational power to derive fully optimal actions (Simon 1955). But this does not imply that they are irrational. In fact, people strive to do the right thing. Their behavior may better be described as a rulegoverned behavior. As argued by psychologists, people tend to follow simple heuristics which have proven to be useful in the recent past (Kahneman, Slovic and Tversky 1986). In addition, natural selection pressure seems to limit the number of applied rules. This observation may be crucial since if one is able to identify the agents' main heuristics, then it should be possible to model their behavior. In our case, two related strands of research are relevant: survey studies and laboratory experiments.

Questionnaire evidence informs us that financial market participants rely on technical and fundamental analysis to determine their investment positions. As reported by Taylor and Allen (1992) and Lui and Mole (1998), most professional traders are familiar with both concepts. For short-term predictions, say up to one week, technical and fundamental analysis are judged as equally important. Which rule is applied in a given situation depends on market circumstances. Remember that technical analysis aims at deriving trading signals out of past price movements (Murphy 1999). Such positive feedback rules are likely to destabilize the markets. The intention of fundamental analysis is to exploit deviations between prices and fundamentals. Betting on mean reversion, however, tends to stabilize the markets.

Smith (1991) pioneered the use of laboratory asset markets to observe investor behavior in a well-defined and controlled environment. In the experiments, each participant 
receives an initial portfolio of cash and stocks and is free to trade. The trading is conducted by computer through local networks. When all participants have entered their action, the next period's price is revealed. The experiments indicate that the participants use simple forms of forecast rules such as extrapolative or regressive predictors. Furthermore, they frequently drove asset prices far above fundamentals, after which the markets crashed. Bubble-and-crash sequences appear to be quite robust, even when all agents know the true fundamental value of the asset. Similar results are reported by Caginalp, Porter and Smith (2001) and Sonnemans et al. (2003). The latter study also documents that the agents' trading may also create quite irregular price trajectories and excess volatility.

The chartist-fundamentalist approach is based on these observations and aims at explaining the complicated price dynamics as observed in actual speculative markets. Some of these models highlight the fact that the agents' trading rules may be non-linear (Day and Huang 1990, Chiarella 1992, Farmer and Joshi 2002). For instance, Day and Huang (1990) assume that chartists generate their orders according to linear trading rules but that the demand of fundamentalists increases exponentially with respect to mispricings. If the price is close to its fundamental, chart orders outweigh fundamental orders and the price is driven away from fundamentals. But the higher the distortion is, the stronger the demand of the fundamentalists becomes and prices are - temporarily - pushed back to fundamentals.

In de Grauwe, Dewachter and Embrechts (1993), fundamentalists are heterogeneous. Their estimates of the long-run equilibrium price are normally distributed around its true value. If the price is close to its long-run equilibrium, half of the fundamentalists think that the market is overvalued whereas the other half think that it is undervalued. As a result, orders of fundamentalists cancel each other out and the destabilizing chartists dominate the market. However, the larger the distance between the price and its long-run equilibrium, the more fundamentalists agree on the future price direction and mean reversion sets in. 
But agents also switch between trading rules. Several notable switching mechanisms have already been developed. Kirman (1991, 1993) explores sudden swings in market opinion due to social interactions. Speculators frequently talk to each other and observe what others do. Coordinated behavior may arise, triggering severe bubbles and crashes. In Brock and Hommes (1997, 1998), agents choose between cheap naive predictors and costly sophisticated predictors. The agents are rational in the sense that they prefer profitable predictors. Suppose that the majority of agents rely on precise predictors. Then prices are driven towards fundamentals. But with prices close to fundamentals, prediction errors of naive rules become small. Since they are relatively cheap, higher profits are generated than with expensive predictors. As the impact of naive rules increases, prices disconnect from fundamentals.

Finally, Lux $(1995,1997,1998)$ combines economic and social factors. On the one hand, agents switch between technical and fundamental analysis because of profit differentials. On the other hand, the mood of chartists depends on social interactions within their group. They may turn from an optimistic into a pessimistic mood and vice versa. Significant bubbles may occur if agents increasingly turn into optimistic chartists. The bubble is stopped when expected arbitrage opportunities make fundamental analysis appear superior.

These contributions do not only produce intricate motion, some of them even generate time series which are not distinguishable from actual time series: Artificial as well as actual prices show bubbles and crashes, excess volatility, fat tails for the distribution of the returns, uncorrelated price changes and volatility clustering. Recent interesting refinements incorporating wealth, learning or other aspects - include Caginalp, Porter and Smith (2000), Cont and Bouchaud (2000), Gaunersdorfer (2000), Lux and Marchesi (2000), de Grauwe and Grimaldi (2002), Chiarella and He (2003), or Rosser, Ahmed and Hartmann (2003).

To sum up, the chartist-fundamentalist approach gives a realistic picture of speculative behavior. Therefore, it seems to be reasonable to employ such a setup as an artificial laboratory to study the effectiveness of certain regulatory policies. Besides theoretical 
reasoning, empirical studies or laboratory experiments, computer simulations may be regarded as an additional instrument to design successful new trading institutions. Simulation studies have the advantage that one can control for all kinds of shocks, measure the variables precisely and produce as many observations as required.

A couple of studies have already followed this avenue. Westerhoff (2003a) reports that trading breaks may successfully limit the destabilizing activity of chartists. Furthermore, Yeh (2003) investigates the consequences of tick price changes on price dynamics while Scalas et al. (2003) study fraudulent behavior such as insider trading. Transaction taxes have recently also received some attention. Ehrenstein (2003) finds that transaction taxes may reduce exchange rate volatility and generate significant tax revenues. Westerhoff (2003b) obtains similar findings but warns that if the tax rate is set too high then too many stabilizing fundamental traders leave the market so that prices stop tracking their fundamentals. Finally, Ehrenstein, Westerhoff and Stauffer (2003) take into account the feedback that reduced speculation via reduced market depth may increase exchange rate variability. They demonstrate that a transaction tax may still reduce volatility and distortion. Note that the latter three papers concentrate on a single foreign exchange market.

The goal of this paper is to analyze the effect of transaction taxes when speculators can trade in more than one market. Multi-asset market models with interacting chartists and fundamentalists are, unfortunately, rare. Westerhoff (2003c) develops a model in which fundamentalists are restricted to a certain market and chartists can wander between markets. Chiarella, Dieci and Gardini (2003) present an interesting framework in which the agents' orders depend on the assets' cross-correlation. Both approaches reveal novel generators of complex endogenous dynamics. For our purpose, however, we have to develop a new model which will be presented in the next section. Our model is inspired by the aforementioned contributions, especially by the type of models surveyed in Hommes (2001). 


\section{The model}

For simplicity, we consider only trading in two speculative markets. The agents can rely on technical or fundamental trading strategies to determine their orders. While technical analysis goes with past price trends, fundamental analysis predicts a convergence towards fundamentals. But the agents are free to trade and so they have five options in total. The agents decide on a certain option, depending on its relative fitness, where the fitness is given as a weighted average of current and past profits. For instance, the strategy "no trading" produces no profits and consequently has a fitness of zero. The decision of the agents is rational in the sense that the higher the fitness of a rule, the more agents will select it. After the agents have decided on a strategy, they submit their orders. Prices adjust with respect to excess demand via a price impact function: Excess buying drives prices up and excess selling drives them down. After the new prices have been revealed, the next trading round begins.

Let us now develop the model. We approximate the price adjustment process by a loglinear price impact function (Farmer and Joshi 2002). Such a function describes the relation between the number of assets bought or sold in a given time interval and the price change caused by these orders. The log prices of markets 1 and 2 in period $t+1$ are given as

$$
S_{t+1}^{1}=S_{t}^{1}+a^{M}\left(W_{t}^{C, 1} D_{t}^{C, 1}+W_{t}^{F, 1} D_{t}^{F, 1}\right)+r_{t}^{M, 1}
$$

and

$$
S_{t+1}^{2}=S_{t}^{2}+a^{M}\left(W_{t}^{C, 2} D_{t}^{C, 2}+W_{t}^{F, 2} D_{t}^{F, 2}\right)+r_{t}^{M, 2}
$$

where $a^{M}$ is a positive price adjustment coefficient, $D^{C, 1}, D^{C, 2}, D^{F, 1}$ and $D^{F, 2}$ stand for the orders due to technical or fundamental analysis rules in markets 1 or 2 , respectively, and $W^{C, 1}$, $W^{C, 2}, W^{F, 1}$ and $W^{F, 2}$ denote the fractions of agents who follow these rules. Accordingly, excess buying (selling) increases (decreases) prices. Since our model represents only a simplification of actual order matching mechanism (e.g. market maker or limit order book) we add random variables $r^{M, 1} \sim \mathrm{N}\left(0, \sigma^{M, 1}\right)$ and $r^{M, 2} \sim \mathrm{N}\left(0, \sigma^{M, 2}\right)$ to the systems' equations. 
Orders generated by technical analysis in markets 1 and 2 are specified as

$D_{t}^{C, 1}=a^{C}\left(S_{t}^{1}-S_{t-1}^{1}\right)+r_{t}^{C, 1}$

and

$D_{t}^{C, 2}=a^{C}\left(S_{t}^{2}-S_{t-1}^{2}\right)+r_{t}^{C, 2}$.

The reaction coefficient $a^{C}$ is positive and captures the strength of positive feedback trading. Although the "philosophy" of technical analysis it to ride on a trend, there exist a myriad of different technical trading rules (Murphy 1999). To capture part of the variety in technical analysis we include random variables $r^{C, 1} \sim \mathrm{N}\left(0, \sigma^{C, 1}\right)$ and $r^{C, 2} \sim \mathrm{N}\left(0, \sigma^{C, 2}\right)$.

Orders produced by fundamental analysis in markets 1 and 2 are written as

$D_{t}^{F, 1}=a^{F}\left(F_{t}^{1}-S_{t}^{1}\right)+r_{t}^{F, 1}$

and

$D_{t}^{F, 2}=a^{F}\left(F_{t}^{2}-S_{t}^{2}\right)+r_{t}^{F, 2}$,

where $a^{F}$ is a positive reaction coefficient and $F^{1}$ and $F^{2}$ are the log fundamental values of markets 1 and 2, respectively. For instance, if an asset is undervalued $(S<F)$, buying is suggested. Fundamental values may change over time due to real shocks. Since modeling the evolution of the fundamentals as random walks has no impact on the results, we set - for the sake of convenience - the fundamental values at constant (i.e. $F^{1}=F^{2}=0$ ). As already remarked by Keynes (1936), it is quite difficult for investors to determine the fundamentals. To incorporate errors in the perception of fundamentals, we buffet (5) and (6) with random variables $r^{F, 1} \sim \mathrm{N}\left(0, \sigma^{F, 1}\right)$ and $r^{F, 2} \sim \mathrm{N}\left(0, \sigma^{F, 2}\right)$.

The agents do not stick to a certain rule/market combination but compare their past performance. To be precise, the agents assign the "no trading" alternative a fitness of zero and compute the fitness of the remaining options as follows

$A_{t}^{C, 1}=\left(S_{t}^{1}-S_{t-1}^{1}\right) D_{t-2}^{C, 1}-2 \operatorname{tax}^{1}\left|D_{t-2}^{C, 1}\right|+b A_{t-1}^{C, 1}$, 
$A_{t}^{F, 1}=\left(S_{t}^{1}-S_{t-1}^{1}\right) D_{t-2}^{F, 1}-2 \operatorname{tax}^{1}\left|D_{t-2}^{F, 1}\right|+b A_{t-1}^{F, 1}$,

$A_{t}^{C, 2}=\left(S_{t}^{2}-S_{t-1}^{2}\right) D_{t-2}^{C, 2}-2 \operatorname{tax}^{2}\left|D_{t-2}^{C, 2}\right|+b A_{t-1}^{C, 2}$

and

$A_{t}^{F, 2}=\left(S_{t}^{2}-S_{t-1}^{2}\right) D_{t-2}^{F, 2}-2 \operatorname{tax}^{2}\left|D_{t-2}^{F, 2}\right|+b A_{t-1}^{F, 2}$.

The first terms of the above equations indicate the most recent performance. Note the timing of the model: Orders submitted in period $\mathrm{t}-2$ are filled at prices in period $\mathrm{t}-1 . \mathrm{D}_{\text {Profits }}$ then depend on prices in period t. The second term reflects the costs of trading with respect to transaction taxes, where $\operatorname{tax}^{1}$ is the tax rate of market 1 and $\operatorname{tax}^{2}$ is the tax rate of market 2 . To realize profits, agents have to off-set their positions, i.e. the tax has to be paid twice. The fitness of the strategies furthermore depends on their past performance (Hommes 2001). The memory parameter $b$ measures how fast current fitness is discounted for strategy selection. For $b=0$, the fitness equals current profits. But the larger the memory of the agents, the more strongly the fitness depends on its past performance. If $b=1$, then the fitness is calculated as the sum over all past profits.

We are interested in how the importance of the strategies evolves over time. In order to simplify the model as far as possible, we do not keep track of the positions of individual agents. As will become clear later, it is the composition of strategies in a market that matters for stability. The percentage of agents choosing a certain option is expressed by a discrete choice model (Manski and McFadden 1981)

$$
\begin{aligned}
& W_{t}^{C, 1}=\frac{\operatorname{Exp}\left[c A_{t}^{C, 1}\right]}{\operatorname{Exp}\left[c A_{t}^{C, 1}\right]+\operatorname{Exp}\left[c A_{t}^{F, 1}\right]+\operatorname{Exp}\left[c A_{t}^{C, 2}\right]+\operatorname{Exp}\left[c A_{t}^{F, 2}\right]+\operatorname{Exp}[0]}, \\
& W_{t}^{F, 1}=\frac{\operatorname{Exp}\left[c A_{t}^{F, 1}\right]}{\operatorname{Exp}\left[c A_{t}^{C, 1}\right]+\operatorname{Exp}\left[c A_{t}^{F, 1}\right]+\operatorname{Exp}\left[c A_{t}^{C, 2}\right]+\operatorname{Exp}\left[c A_{t}^{F, 2}\right]+\operatorname{Exp}[0]},
\end{aligned}
$$

\footnotetext{
${ }^{1}$ A so-called market order is a request to transact immediately at the best available price. In fact, the fill price is typically unknown to the speculator.
} 


$$
\begin{aligned}
& W_{t}^{C, 2}=\frac{\operatorname{Exp}\left[c A_{t}^{C, 2}\right]}{\operatorname{Exp}\left[c A_{t}^{C, 1}\right]+\operatorname{Exp}\left[c A_{t}^{F, 1}\right]+\operatorname{Exp}\left[c A_{t}^{C, 2}\right]+\operatorname{Exp}\left[c A_{t}^{F, 2}\right]+\operatorname{Exp}[0]}, \\
& W_{t}^{F, 2}=\frac{\operatorname{Exp}\left[c A_{t}^{F, 2}\right]}{\operatorname{Exp}\left[c A_{t}^{C, 1}\right]+\operatorname{Exp}\left[c A_{t}^{F, 1}\right]+\operatorname{Exp}\left[c A_{t}^{C, 2}\right]+\operatorname{Exp}\left[c A_{t}^{F, 2}\right]+\operatorname{Exp}[0]}
\end{aligned}
$$

and

$W_{t}^{O}=1-W_{t}^{C, 1}-W_{t}^{F, 1}-W_{t}^{C, 2}-W_{t}^{F, 2}$

The higher the fitness of a strategy, the more agents will rely on it. Parameter $c$ captures how sensitive the mass of traders is to selecting the most attractive strategy. The higher $c$ is, the more agents will select the option with the highest fitness. If $c$ goes to plus infinity, all agents follow the option with the highest fitness. For $c=0$, each option is used by 20 percent of the agents, regardless of its profitability. In this sense, $c$ reflects the rationality of the agents.

\section{The dynamics without transaction taxes}

\subsection{Calibration}

The evolution of the prices is due to high-dimensional non-linear laws of motion which preclude closed analysis. Therefore, we continue with simulation analysis on the basis of the parameter setting presented in table 1. Unfortunately, no empirical guidance exists on how to select the parameters. We have attempted to calibrate the model such that it produces reasonable dynamics. Note that the better the model matches the behavior of real prices, the more reliable the policy experiments are. Although numerical investigations are sometimes criticized one should note that it is often quite simple to replicate the results and to test their robustness. Our system is completely described by (1)-(15) and can be run on any modern computer. 


\subsection{How the model works}

Let us first try to understand the working of the model. Figure 1 depicts a typical simulation run with 5000 observations. Since the model is calibrated to daily data, 5000 observations corresponds to a time span of about 25 years. The first two panels show the development of $\log$ prices in markets 1 and 2, respectively. Prices apparently circle in an intricate way around their fundamentals. In some periods, prices are close to fundamentals, yet also pronounced bubbles and crashes occasionally occur. Market 2, for example, is overvalued by more than 70 percent around period 1400 . The last two panels display log price changes, i.e. returns, in markets 1 and 2, respectively. Returns are often used to measure volatility. As can be seen, extreme price changes may be as large as 10 percent. Moreover, volatility tends to cluster, that is, periods of low volatility alternate with periods of high volatility.

\section{Figure 1 goes about here}

What drives the dynamics is the evolution of the importance of the strategies. The central panel presents the impact of the five strategies in the time domain. From bottom to top we see the weight of chartism in market 1 (black), fundamentalism in market 1 (white), "no trading" (grey), fundamentalism in market 2 (grey) and chartism in market 2 (black). On average, each strategy is used in about 20 percent of the time. Destabilizing speculation in form of technical analysis obviously does survive natural selection pressure. Moreover, it is at least as profitable as fundamental analysis. The importance of the strategies, however, varies gradually over time. Note that whenever the composition of chartism, fundamentalism and no trading in a market changes, the stability of the market is affected. For instance, many agents rely on technical analysis in market 1 around period 500. Since technical analysis is destabilizing, the price of market 1 is pushed away from its fundamental value and volatility is relatively high. Between periods 4000 and 4500, chartism is neither popular in market 1 nor in market 2. Instead agents prefer fundamentalism or simply abstain from trading. Now prices are close to fundamentals and volatility is low. 


\subsection{Stylized facts}

Next we conduct a more comprehensive Monte Carlo analysis to check to which extent our model is able to match the statistical properties of real speculative prices. According to Cont (2001), Lux and Ausloos (2002) and Johansen and Sornette (2003), speculative markets are characterized by five universal features: (1) prices are distorted in the form of bubbles and crashes, (2) price volatility is higher than warranted by fundamentals, (3) the distribution of log price changes is leptokurtic, (4) daily log price changes are close to serially independent, and (5) daily absolute log price changes display strong autocorrelation.

With the help of some simple statistics we are able to quantify these phenomena. Returns are defined as log price changes

$r_{t}=S_{t}-S_{t}$

We compute distortions as the average absolute distance between log prices and $\log$ fundamentals

$D=\frac{1}{T} \sum_{t=1}^{T}\left|S_{t}-F\right|$

and volatility as the average absolute return

$V=\frac{1}{T} \sum_{t=1}^{T}\left|r_{t}\right|$,

where $T$ denotes the sample length. The kurtosis is calculated as

$K=\frac{\frac{1}{T} \sum_{t=1}^{T}\left(r_{t}-\bar{r}\right)^{4}}{\left(\frac{1}{T} \sum_{t=1}^{T}\left(r_{t}-\bar{r}\right)^{2}\right)^{2}}$,

where $\bar{r}$ is the average return. Remember that Normal distributions have a kurtosis of 3 and that excess kurtosis, i.e. leptokurtic behavior, is defined as $K-3>0$. Autocorrelation coefficients with lag size $k$ for the returns are given as 
$a c_{r}^{k}=\frac{\sum_{t=1}^{T-k}\left(r_{t}-\bar{r}\right)\left(r_{t+k}-\bar{r}\right)}{\sum_{t=1}^{T}\left(r_{t}-\bar{r}\right)\left(r_{t}-\bar{r}\right)}$.

If the data is generated by Gaussian white noise, then the autocorrelation coefficients should lie within $\pm 2 / \sqrt{T}$ about 95 percent of the time. Significant autocorrelation coefficients obviously indicate temporal dependence. Autocorrelation coefficients for absolute returns are computed analogously.

Table 2 presents some estimates of these statistics. Since markets 1 and 2 are symmetrical we can restrict the analysis to one market. We have generated 1000 simulations runs with 5000 observations each. Reported are the 5, 25, 50, 75 and 95 percent quantiles. Overall, there is little variation in the main statistics. Extremely negative returns hover between -16.9 and -9.7 percent whereas extreme positively returns scatter between 9.8 and 17.3 percent. The median volatility is 1.3 percent. 90 percent of the mispricing estimates range between 7.9 and 15.7 percent. At least more than 95 percent of the simulation runs show excess kurtosis where the mean kurtosis is $8.6 .^{\mathrm{Q}}$ Almost all autocorrelation coefficients for raw returns are not significant, implying that the evolution of the prices is close to a random walk. The autocorrelation coefficients for absolute returns are significant. Further simulations taking into account higher lag sizes demonstrate that the autocorrelation function is slowly decaying, revealing quite long memory in volatility, up to 100 lags.

Table 2 goes about here

Table 3 contains similar estimates for time series of the Dow Jones industrial average, the German share price index, mark-dollar exchange rates, mark-yen exchange rates and crude oil, gold and silver prices. Depending on the time series, daily returns may be as large

\footnotetext{
${ }^{2}$ As noted by Lux (2001), the fourth moment of the distribution of the returns may not exist. Thus, the Hill tail index estimator should be used to describe the fattailedness of the distribution of the returns. In our case, 90 percent of these estimates lie between 2.5 and 3.3, which is in good agreement with results obtained for actual speculative markets.
} 
as 40 percent (crude oil). Extreme returns for commodities and stock markets scatter between 7.3 and 25.7 percent while exchange rates vary less dramatically. Overall, estimates of volatility hover between 0.44 and 1.73 percent. Since the fundamental values of these markets are unknown, we are unable to compute the distortion. However, both extreme returns and high volatility are indicators of distorted prices. Evidence of bubbles and crashes in financial markets is discussed in further detail by Johansen and Sornette (2003).

All time series display high kurtosis with estimates ranging from 7.0 to 71.1 . The autocorrelation coefficients of raw returns are, with very few exceptions, not significant but temporal dependence in volatility is clearly visible. Comparing tables 2 and 3 , one may conclude that our simple model has the power to mimic some important stylized facts of speculative markets quite well. Therefore, we use the model as a computer laboratory to conduct some artificial policy experiments in the next section.

------ Table 3 goes about here ---------

\section{The dynamics with transaction taxes}

We explore the effectiveness of transaction taxes in two steps. In section 5.1, we investigate the consequences of transaction taxes imposed in one market only. In section 5.2, the agents are confronted with uniform transaction taxes in both markets.

\subsection{Transaction tax in one market}

Let us start with an example. Figure 2 displays a simulation run in which a regulator has imposed a transaction tax of 0.25 percent in market 1 . Figure 2 can be compared directly with figure 1 since it is based on the same seed of random variables; differences in the dynamics are solely due to taxation. As can be seen, even a low tax rate of 0.25 percent may have a quite dramatic impact: While market 1 has become less distorted and less volatile, market 2 shows stronger bubbles and crashes and higher volatility than before.

The central panel reveals the reasons for this outcome. Transaction taxes interfere with 
the evolutionary competition between the agents' strategies. Agents stop following technical analysis rules in market 1 and, as a result, price variability declines. Also the impact of fundamentalism has weakened in this market, yet not as strongly. Due to the reduction of fundamental trading in market 1 distortions do not vanish completely. Some agents retreat from trading but both chartism and fundamentalism increase in market 2. Hence, price fluctuations are more pronounced here. To sum up, market 1 benefits from the imposition of the transaction tax in terms of higher stability at the cost of market's 2 stability.

\section{-------- Figure 2 goes about here ---------}

To evaluate the effect of transaction taxes a more general kind of analysis is needed. Figure 3 presents the impact of increasing transaction taxes in market 1 on volatility, distortion, chartism and fundamentalism in market 1 (left-hand panels) and market 2 (righthand panels), respectively. The tax rate is increased in 20 steps from 0 to 0.5 percent. All estimates are computed as averages over 10 simulation runs, each time series containing 5000 observations. For tax rates up to 0.5 percent, volatility in market 1 decreases from about 1.3 percent to 0.8 percent. But volatility in market 2 increases from 1.3 to 1.6 percent at the same time. The distortion in market 2 remains almost constant, but first decreases in market 1 from 12 to 7.5 percent. If the tax rate is set higher than 0.25 percent, mispricings in market 2 start to grow again. At a tax rate of 0.5 percent, the distortion has climbed to 10 percent.

The results may be understood by inspecting the bottom 4 panels. Transaction taxes obviously change the relative importance of the five strategies. We see that both technical and fundamental trading is crowded out in market 1 . This first decreases volatility and distortion but when the impact of fundamentalism is too low, prices stop tracking their fundamentals. Furthermore, the migration of traders from market 1 to market 2 increases the volatility in market 2. Since the increments in fundamentalism and chartism are roughly equal, distortion remains almost constant. 


\subsection{Transaction tax in both markets}

Note that when market 1 imposes a transaction tax, market 2 becomes destabilized. The regulators of market 2 may thus also want to introduce a transaction tax. Figure 4 shows the dynamics when markets 1 and 2 impose a uniform transaction tax of 0.25 percent. Now both markets are stabilized, i.e. we observe less mispricing and price variability. The central panel depicts a strong increase in the weight of inactive traders. Many agents stop using technical analysis, but the impact of fundamental analysis is not diminished by the levy.

\section{--------- Figure 4 goes about here ----------}

In figure 5 we explore the robustness of the findings in the same way as we did in figure 3. The results are striking. If regulators introduce a uniform tax on all transactions, then volatility and distortion decrease in both markets. The bottom 4 panels raise an interesting question: Why do agents stop using chart trading rules yet not fundamental trading rules. Remember that Keynes (1936) already claimed that a transaction tax would mitigate the predominance of short-term speculation over long-term investment. Here, agents apply technical and fundamental analysis on a daily basis to take their orders. But there is an important difference between the two strategies. As long as a market is either over- or undervalued, fundamental analysis consistently suggests trading in the same direction. For instance, if a market is undervalued for three years in a row, then fundamental analysis generates buying signals over the entire period. Fundamental analysis therefore has an implicit long-term perspective. In contrast, technical analysis rules follow the current price trend, which changes its sign frequently. Technical analysis is in fact equivalent to short-term speculation. Our simulation analysis demonstrates that Keynes was right: Transaction taxes penalize destabilizing behavior more than stabilizing behavior even if both types of trading rules are applied at the same frequency.

\footnotetext{
---------- Figure 5 goes about here ----------
} 


\section{Conclusions}

We believe that chartist-fundamentalist models can be instrumental in helping regulators of markets determine better policy. We present a model in which agents are free to trade in two different markets applying technical or fundamental analysis. The agents prefer rules which have performed well in the past. As it turns out, the agents judge on average technical and fundamental analysis as equally useful, which is consistent with survey and experimental data. An unending competition between the trading strategies creates, however, complex price dynamics. Simulations reveal that the model is able to mimic the behavior of real speculative markets quite well. In particular, artificial time series are portrayed by intricate price fluctuations, bubbles and crashes, excess volatility, leptokurtic returns and clustered volatility.

As ventured by Keynes (1936) and Tobin (1978), small transaction taxes reduce price variability by rendering high-frequency trend chasing unprofitable without affecting longterm fundamental investments. Our model allows this hypothesis to be tested. We find that if a transaction tax is imposed in one market, speculators leave this market. Hence, this market becomes less distorted and less volatile. However, the agents do not simply vanish but reappear on another market, which in turn becomes destabilized. Regulators who impose a levy in their market may force regulators of other markets to follow. If all markets introduce a uniform transaction tax, then economically unjustified speculation is dampened, agents focus more strongly on fundamental data, and all markets are stabilized.

Although increasing evidence suggests that transaction taxes may be an effective policy tool, more research is still needed. For instance, it would be interesting to see a model in which the behavior of individual agents is monitored. Wealth effects and demand functions depending on the assets' cross-correlation may be of relevance. In addition, one may also try to test this policy within a laboratory setting with real agents. We hope that our study will attract more academic attention into this important and exciting research direction. 


\section{References}

Brock, W. and Hommes, C. (1997): A rational route to randomness. Econometrica, 65, 10591095.

Brock, W. and Hommes. C. (1998): Heterogeneous beliefs and routes to chaos in a simple asset pricing model. Journal of Economic Dynamics and Control, 22, 1235-1274.

Caginalp, G., Porter, D. and Smith, V. (2000): Overreactions, momentum, and price bubbles in laboratory and field asset markets. Journal of Psychology and Financial Markets, 1, 2448.

Caginalp, G., Porter, D. and Smith, V. (2001): Financial bubbles: Excess cash, momentum, and incomplete information. Journal of Psychology and Financial Markets, 2, 80-99.

Chiarella, C. (1992): The dynamics of speculative behavior. Annals of Operations Research, 37, 101-123.

Chiarella, C. and He, X.-Z. (2003): Dynamics of beliefs and learning under $a_{-} L$ processes the heterogeneous case. Journal of Economic Dynamics and Control, 27, 503-531.

Chiarella, C., Dieci, R. and Gardini, L. (2003): Diversification and dynamics of asset prices under heterogeneous beliefs. University of Technology Sydney, Working Paper.

Cont, R. and Bouchaud, J.-P. (2000): Herd behavior and aggregate fluctuations in financial markets. Macroeconomic Dynamics, 4, 170-196.

Cont, R. (2001): Empirical properties of asset returns: Stylized facts and statistical issues. Quantitative Finance, 1, 223-236.

Day, R. and Huang, W. (1990): Bulls, bears and market sheep. Journal of Economic Behavior and Organization, 14, 299-329.

De Grauwe, P., Dewachter, H. and Embrechts, M. (1993): Exchange rate theory - chaotic models of foreign exchange markets. Blackwell: Oxford.

De Grauwe, P. and Grimaldi, M. (2002): The exchange rate in a model with heterogeneous agents and transaction costs. CESifo Working Paper No. 792.

Ehrenstein, G. (2003): Cont-Bouchaud percolation model including Tobin tax. International Journal of Modern Physics C, 13, 1323-1331.

Ehrenstein, G., Westerhoff, F. and Stauffer, D. (2003): Tobin tax and market depth. Preprint available at: arXiv.org/abs/cond-mat/0311581.

Eichengreen, B., Tobin, J. and Wyplosz, C. (1995): Two cases for sand in the wheels of international finance. Economic Journal, 105, 162-172.

Farmer, D. and Joshi, S. (2002): The price dynamics of common trading strategies. Journal of Economic Behavior and Organization, 49, 149-171.

Frankel, J. (1996): Recent exchange-rate experience and proposals for reform. American Economic Review, 86, 15-158.

Gaunersdorfer, A. (2000): Endogenous fluctuations in a simple asset pricing model with heterogeneous agents. Journal of Economic Dynamics and Control, 9, 5-30.

Haq, M., Kaul, I. and Grunberg, I. (1996): The Tobin tax: Coping with financial volatility. Oxford University Press: New York.

Hommes, C. (2001): Financial markets as nonlinear adaptive evolutionary systems. Quantitative Finance, 1, 149-167.

Johansen, A. and Sornette, D. (2003): Endogenous versus exogenous crashes in financial markets. Journal of Economic Dynamics and Control (in press).

Kahneman, D., Slovic, P. and Tversky, A. (1986): Judgment under uncertainty: Heuristics and biases. Cambridge University Press: Cambridge.

Keynes, J.M. (1936): The general theory of employment, interest, and money. Harcourt Brace: New York.

Kirman, A. (1991): Epidemics of opinion and speculative bubbles in financial markets. In: Taylor, M. (Ed.): Money and Financial Markets, Blackwell: Oxford, 354-368. 
Kirman, A. (1993): Ants, rationality, and recruitment. Quarterly Journal of Economics, 108, 137-156.

Lui, Y.-H. and Mole, D. (1998): The use of fundamental and technical analysis by foreign exchange dealers: Hong Kong evidence. Journal of International Money and Finance, 17, 535-545.

Lux, T. (1995): Herd behavior, bubbles and crashes. Economic Journal, 105, 881-896.

Lux, T. (1997): Time variation of second moments from a noise trader/infection model. Journal of Economic Dynamics and Control, 22, 1-38.

Lux, T. (1998): The socio-economic dynamics of speculative markets: Interacting agents, chaos, and the fat tails of return distributions. Journal of Economic Behavior and Organization, 33, 143-165.

Lux, T. (2001): The limiting extremal behavior of speculative returns: An analysis of intradaily data from the Frankfurt stock exchange. Applied financial economics, 11, 299-315.

Lux, T. and Marchesi, M. (2000): Volatility clustering in financial markets: A microsimulation of interacting agents. International Journal of Theoretical and Applied Finance, 3, 675-702.

Lux, T. and Ausloos, M. (2002): Market fluctuations I: Scaling, multiscaling, and their possible origins. In: Bunde, A., Kropp, J. and Schellnhuber, H. (Eds.): Science of Disaster: Climate Disruptions, Heart Attacks, and Market Crashes. Springer, Berlin, 373-410.

Manski, C. and McFadden, D. (1981): Structural analysis of discrete data with econometric applications. MIT Press: Cambridge.

Murphy, J. (1999): Technical analysis of financial markets. New York Institute of Finance: New York.

Rosser, J.B., Ahmed, E. and Hartmann, G. (2003): Volatility via social flaring. Journal of Economic Behavior and Organization, 50, 77-87.

Scalas, E., Cincotti, S., Dose, C. and Raberto, M. (2003): Fraudulent behavior in an artificial financial market. University of Genoa, Working Paper.

Simon, H. (1955): A behavioral model of rational choice. Quarterly Journal of Economics, 9, 99-118.

Smith, V. (1991): Papers in experimental economics. Cambridge University Press: Cambridge.

Sonnemans, J., Hommes, C., Tuinstra, J. and van de Velden, H. (2003): The instability of a heterogeneous cobweb economy: a strategy experiment on expectation formation. Journal of Economic Behavior and Organization, in press.

Spahn, B. (2002): On the feasibility of a tax on foreign exchange transactions. Report to the Federal Ministry for Economic Cooperation and Development, Bonn.

Taylor, M. and Allen, H. (1992): The use of technical analysis in the foreign exchange market. Journal of International Money and Finance, 11, 304-314.

Tobin, J. (1978): A proposal for international monetary reform. Eastern Economic Journal, 4, 153-159.

Westerhoff, F. (2003a): Speculative markets and the effectiveness of price limits. Journal of Economic Dynamics and Control, 28, 493-508.

Westerhoff, F. (2003b): Heterogeneous traders and the tobin tax. Journal of Evolutionary Economics, 13, 53-70.

Westerhoff, F. (2003c): Multi-asset market dynamics. University of Osnabrueck, Working Paper Nr. 2003/01.

Yeh, C. (2003): Tick size and market performance. Yuan Ze University, Working Paper. 


\begin{tabular}{|c|c|c|}
\hline$a^{M}=1$ & $a^{C}=0.05$ & $a^{F}=0.05$ \\
\hline $\operatorname{tax}^{1}=\operatorname{tax}^{2}=0$ & $b=0.975$ & $c^{=}=300$ \\
\hline$\sigma^{M, 1}=\sigma^{M, 2}=0.01$ & $\sigma^{C, 1}=\sigma^{C, 2}=0.05$ & $\sigma^{F, 1}=\sigma^{F, 2}=0.01$ \\
\hline
\end{tabular}

Table 1: Parameter setting. 


\begin{tabular}{|c|c|c|c|c|c|}
\hline Quantile & $r_{\min }$ & $r_{\max }$ & $V$ & $D$ & $K$ \\
\hline 0.05 & -16.9 & 09.8 & 1.15 & 07.9 & 06.5 \\
\hline 0.25 & -14.7 & 11.7 & 1.23 & 09.5 & 07.8 \\
\hline 0.50 & -13.1 & 13.1 & 1.30 & 10.7 & 08.6 \\
\hline 0.75 & -11.7 & 14.5 & 1.36 & 12.3 & 09.5 \\
\hline 0.95 & -09.7 & 17.3 & 1.50 & 15.7 & 10.9 \\
\hline
\end{tabular}

\begin{tabular}{|c|c|c|c|c|c|}
\hline Quantile & $a c_{r}^{1}$ & $a c_{r}^{2}$ & $a c_{r}^{3}$ & $a c_{r}^{4}$ & $a c_{r}^{5}$ \\
\hline 0.05 & -0.02 & -0.04 & -0.03 & -0.03 & -0.04 \\
\hline 0.25 & 0.01 & -0.01 & -0.01 & -0.01 & -0.03 \\
\hline 0.50 & 0.03 & 0.01 & 0.01 & 0.01 & 0.00 \\
\hline 0.75 & 0.06 & 0.03 & 0.02 & 0.03 & 0.02 \\
\hline 0.95 & 0.10 & 0.07 & 0.05 & 0.06 & 0.05 \\
\hline
\end{tabular}

\begin{tabular}{|c|c|c|c|c|c|}
\hline Quantile & $a c_{|r|}^{1}$ & $a c_{|r|}^{2}$ & $a c_{|r|}^{3}$ & $a c_{|r|}^{4}$ & $a c_{|r|}^{5}$ \\
\hline 0.05 & 0.17 & 0.16 & 0.15 & 0.15 & 0.15 \\
\hline 0.25 & 0.23 & 0.23 & 0.22 & 0.21 & 0.21 \\
\hline 0.50 & 0.27 & 0.27 & 0.26 & 0.25 & 0.25 \\
\hline 0.75 & 0.31 & 0.31 & 0.30 & 0.29 & 0.28 \\
\hline 0.95 & 0.35 & 0.35 & 0.35 & 0.34 & 0.33 \\
\hline
\end{tabular}

Table 2: Stylized facts of artificial financial markets. Since both markets are symmetrical, we only report estimates for one market. The quantiles of the statistics are calculated on the basis of 1000 simulation runs with 5000 observations each. Parameter setting as in table 1. 


\begin{tabular}{|c|c|c|c|c|c|}
\hline Series & $r_{\text {min }}$ & $r_{\max }$ & $V$ & $D$ & $K$ \\
\hline DJI & -25.6 & 9.7 & 0.70 & - & 71.1 \\
\hline DAX & -13.7 & 7.3 & 0.81 & - & 12.3 \\
\hline DEM/USD & -05.8 & 04.9 & 0.50 & - & 07.0 \\
\hline DEM/JPY & -03.8 & 08.9 & 0.44 & - & 14.0 \\
\hline Crude Oil & -40.6 & 19.2 & 1.73 & - & 24.1 \\
\hline Gold & -14.2 & 12.5 & 0.82 & - & 15.9 \\
\hline Silver & -25.7 & 33.2 & 1.32 & - & 30.7 \\
\hline
\end{tabular}

\begin{tabular}{|c|c|c|c|c|c|}
\hline Series & $a c_{r}^{1}$ & $a c_{r}^{2}$ & $a c_{r}^{3}$ & $a c_{r}^{4}$ & $a c_{r}^{5}$ \\
\hline DJI & 0.04 & -0.04 & -0.02 & -0.02 & 0.02 \\
\hline DAX & 0.03 & -0.05 & -0.01 & 0.01 & 0.02 \\
\hline DEM/USD & -0.03 & 0.00 & 0.03 & -0.01 & 0.01 \\
\hline DEM/JPY & 0.04 & 0.01 & -0.02 & 0.00 & 0.00 \\
\hline Crude Oil & 0.00 & -0.06 & -0.07 & 0.03 & -0.04 \\
\hline Gold & -0.07 & 0.01 & 0.04 & -0.01 & -0.01 \\
\hline Silver & 0.00 & -0.01 & 0.01 & -0.04 & 0.01 \\
\hline
\end{tabular}

\begin{tabular}{|c|c|c|c|c|c|}
\hline Series & $a c_{|r|}^{1}$ & $a c_{|r|}^{2}$ & $a c_{|r|}^{3}$ & $a c_{|r|}^{4}$ & $a c_{|r|}^{5}$ \\
\hline DJI & 0.17 & 0.16 & 0.17 & 0.12 & 0.17 \\
\hline DAX & 0.24 & 0.27 & 0.26 & 0.22 & 0.22 \\
\hline DEM/USD & 0.15 & 0.15 & 0.16 & 0.20 & 0.14 \\
\hline DEM/JPY & 0.24 & 0.20 & 0.18 & 0.19 & 0.16 \\
\hline Crude Oil & 0.20 & 0.22 & 0.23 & 0.20 & 0.22 \\
\hline Gold & 0.38 & 0.37 & 0.33 & 0.35 & 0.34 \\
\hline Silver & 0.37 & 0.31 & 0.30 & 0.30 & 0.32 \\
\hline
\end{tabular}

Table 3: Stylized facts of actual financial markets. Daily data for the Dow Jones industrial average (1975-2000), the German share price index (1975-2000), mark-dollar exchange rates (1974-1998), mark-yen exchange rates (1974-1998), crude oil prices for 1 barrel in USD (1986-2000), gold prices for 1 troyounce in USD (1975-2000), and silver prices for 1 troyounce in USD (1975-2000). 

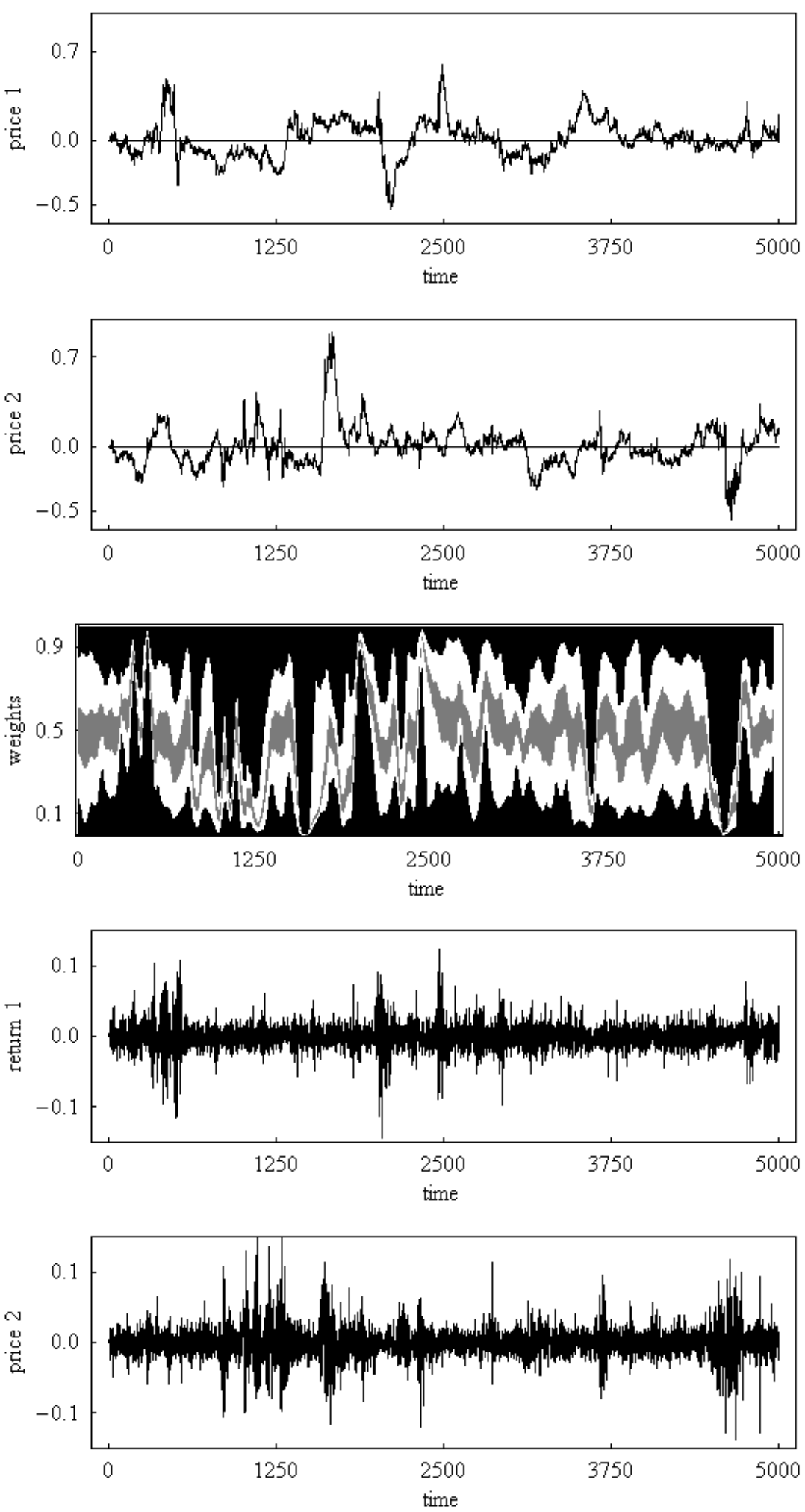

Figure 1: The first, second, third, fourth and fifth panels show $\log$ prices of market $1, \log$ prices of market 2, weights of the traders' strategies (from bottom to top: chartism in market 1 (black), fundamentalism in market 1 (white), no trading (grey), fundamentalism in market 2 (white), and chartism in market 2), returns of market 1 and returns of market 2, respectively. Parameter setting as in table 1, 5000 observations. 

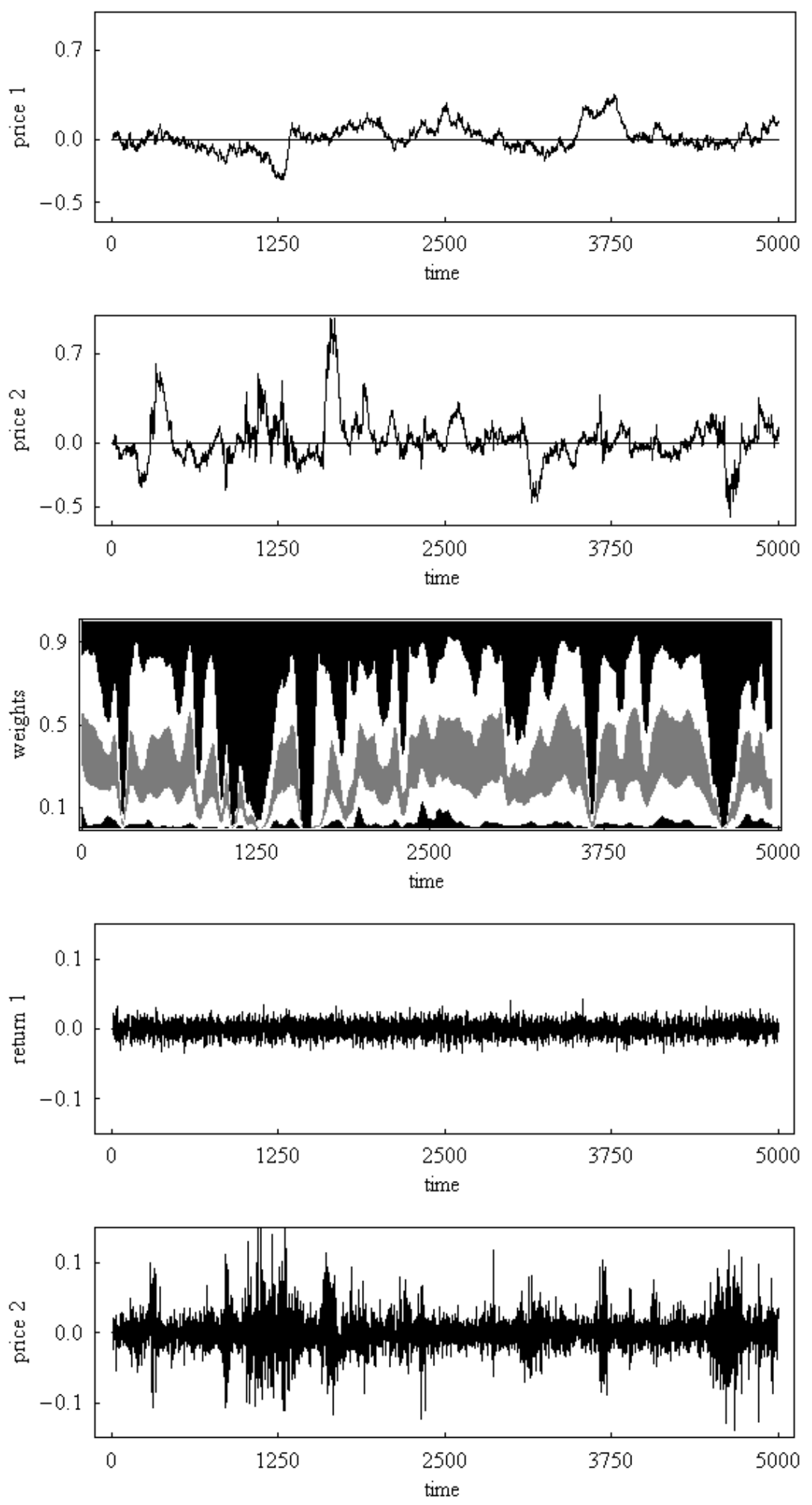

Figure 2: The first, second, third, fourth and fifth panels show $\log$ prices of market $1, \log$ prices of market 2, weights of the traders' strategies (from bottom to top: chartism in market 1 (black), fundamentalism in market 1 (white), no trading (grey), fundamentalism in market 2 (white), and chartism in market 2), returns of market 1 and returns of market 2 , respectively. Parameter setting as in table 1 , but a transaction tax of 0.25 percent is imposed in market 1 , 5000 observations. 

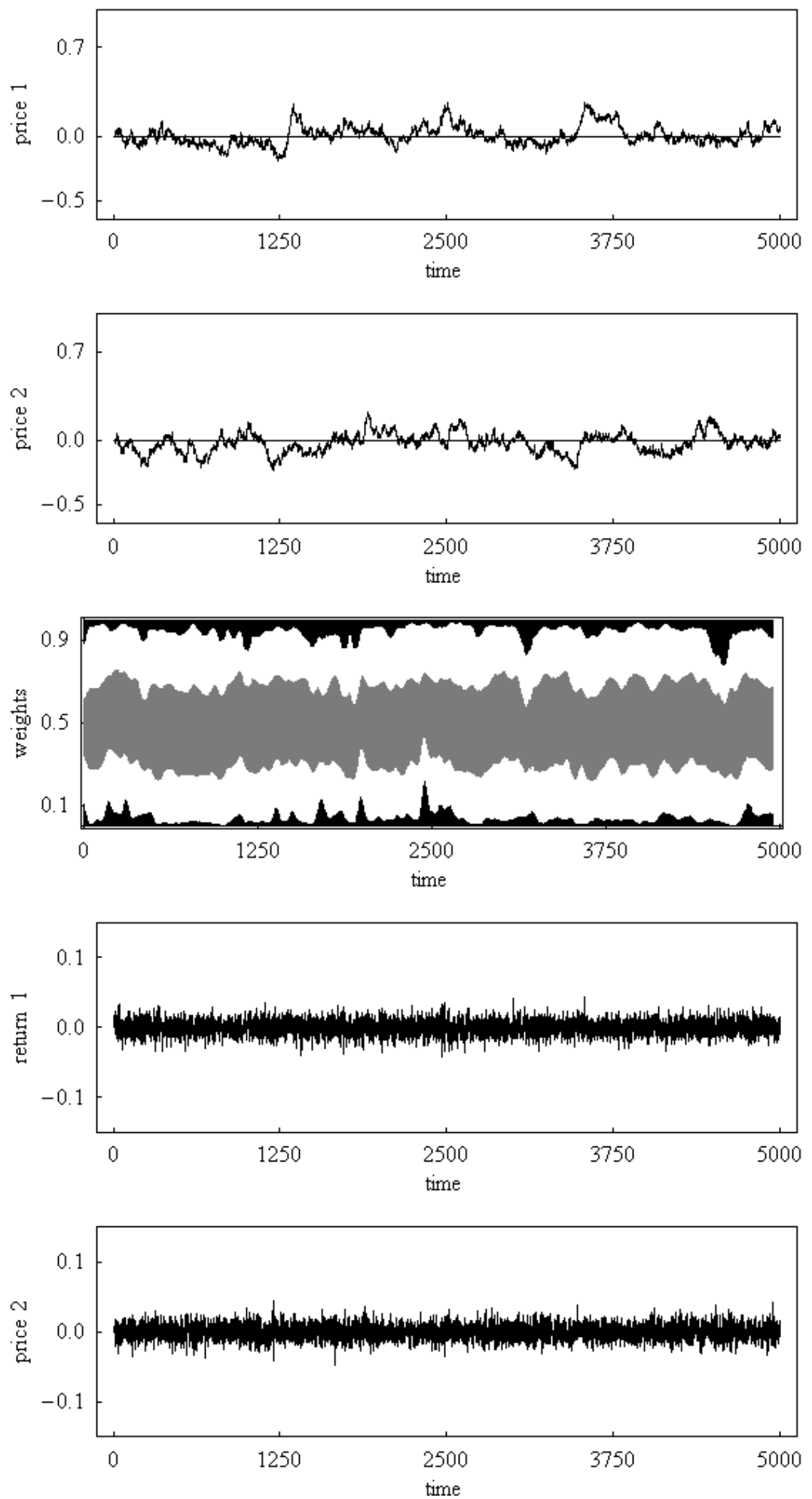

Figure 3: The first, second, third, fourth and fifth panels show log prices of market $1, \log$ prices of market 2, weights of the traders' strategies (from bottom to top: chartism in market 1 (black), fundamentalism in market 1 (white), no trading (grey), fundamentalism in market 2 (white), and chartism in market 2), returns of market 1 and returns of market 2, respectively. Parameter setting as in table 1 , but a transaction tax of 0.25 percent is imposed in both markets, 5000 observations. 

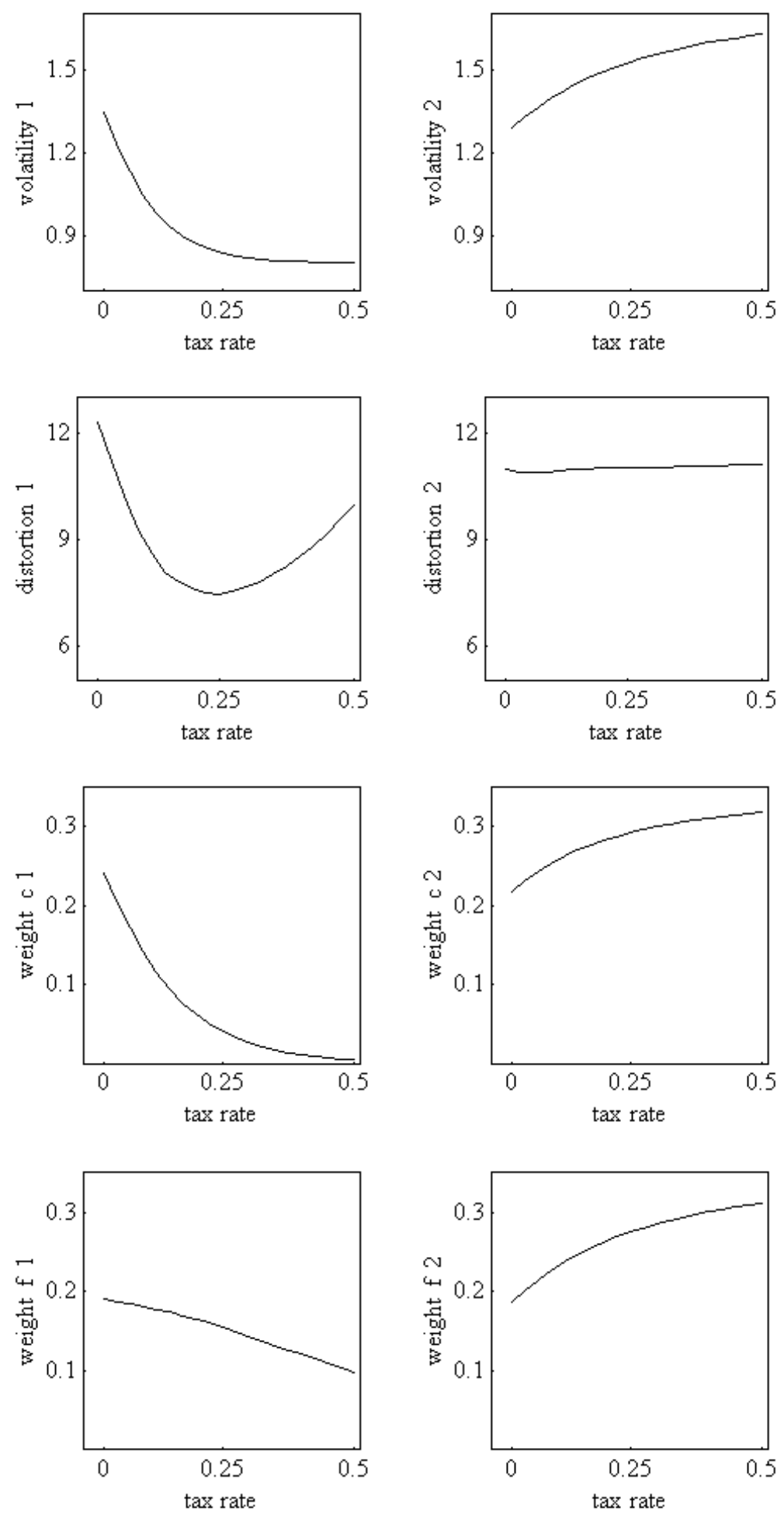

Figure 4: The first, second, third and fourth lines of panels display the impact of a transaction tax imposed in market 1 on the volatility, distortion, weight of chartism and weight of fundamentalisms. The left-hand panels stand for market 1 while the right-hand panels stand for market 2. The tax rate is increased in 20 steps from 0 to 0.5 percent. The statistics are computed as averages over 10 simulation runs, each containing 5000 observations. The other parameters are as in table 1. 



Figure 5: The first, second, third and fourth lines of panels display the impact of a transaction tax imposed in both markets on the volatility, distortion, weight of chartism and weight of fundamentalisms. The left-hand panels stand for market 1 while the right-hand panels stand for market 2. The tax rate is increased in 20 steps from 0 to 0.5 percent. The statistics are computed as averages over 10 simulation runs, each containing 5000 observations. The other parameters are as in table 1. 